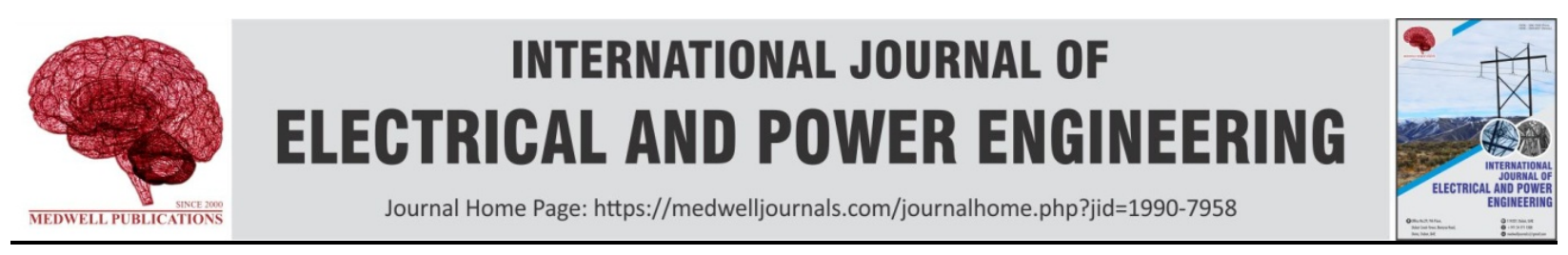

\title{
Analysis of Transient Stability of IEEE-9 Bus System Under Multiple Contingencies
}

\author{
Naveed Anwar, Aamir Hanif, Hafiz Farhaj Khan, Mian Farhan Ullah and Waqas Ahmed \\ Wah Engineering College, University of Wah, Wah, Pakistan
}

Key words: Transient stability, IEEE-9 bus system, critical time, rotor angle and power world simulator, concluded, investigate

\author{
Corresponding Author: \\ Naveed Anwar \\ Wah Engineering College, University of \\ Wah, Wah, Pakistan \\ Page No.: 19-29 \\ Volume: 13, 02, 2019 \\ ISSN: $1990-7958$ \\ International Journal of Electrical and Power \\ Engineering \\ Copy Right: Medwell Publications
}

\begin{abstract}
The determination of the stability of a power system is a crucial step in the power system analysis. The objective of this study is to understand and investigate the transient stability of IEEE 9-bus system that consists of three generators and nine buses. For this, load flow analysis is firstly performed to determine the pre-fault condition in the system. Fast fault clearing time and load switching is then analysed to determine the system stability. For the transient stability analysis, Euler and Runga method are compared and variations in rotor angle and frequency of the system under different fault conditions are analysed. The simulations are done on Power Word Simulator Software. It is concluded that power system should have very low critical clearing time to operate the relays if faulty section is isolate within very short time, thus, the system can obtain the stability otherwise it will go out of synchronism.
\end{abstract}

\section{INTRODUCTION}

Generation, transmission and distribution are generally, the three steps in the power system. The power system is designed to supply continuous power by maintaining the voltage stability even in the presence of lightning, short circuit among the phase wires of the transmission lines and the ground faults. Due to these aforementioned faults, one or many generators may be severely disturbed causing a gap between demand and generation (Kundur, 1994a, b).

As power demand is escalating day by day which results in installation of bigger systems raising the issue of synchronization. Therefore, an increase in the use of electricity and demand forecasting for upcoming development has becoming, gradually, complex. This increase in electricity demand causing overloading of the power lines. Another important issue is that the overloading causes the voltage at each bus to reduce and efficiency of the generators decreases to supply active and reactive power to the system under an abnormal operation of a power system representing a contingency situation. Operation and system operators need to take steps to bring back the power system in safe operation. To resolve these glitches of overloaded transmission lines and increasing load demand, two solutions can be useful one is by increasing power generation and another by constructing a new transmission line.
The stability of the power system has been and remains a major concern in system operation. In designing of an electric power system, analysis of transient stability is very important. Transient stability assesses the power system's capability to sustain large disturbances and to persist in normal operating conditions. The disturbances can be faults such as transmission line short circuit, losses of generator and losses of load. They all result in a large deviation of the generator rotor angle and also effect the power flow, bus voltage and other system variables resulting in partial loss or loss of transmission network.

Steady state stability only deals with operating environments whereas transient stability analysed operating environments as well as disturbances. A frequent investigation is required for various types of disturbances (Duan et al., 2016). Classification of power system stability is critical for a good understanding of power reliability. Power system stability is consequently classified according to the nature of system instability (voltage and frequency stability), magnitude of disturbances (large and small disturbances) and long term and short term stability (time-frame stability). The instability of the power system is a complex issue, since, it can take many forms and can be related to many factors. Figure 1 shows a detailed classification that defines three main categories of power system stability. The considerations that are taken to counter system instability include the physical nature of the instability, loss of 


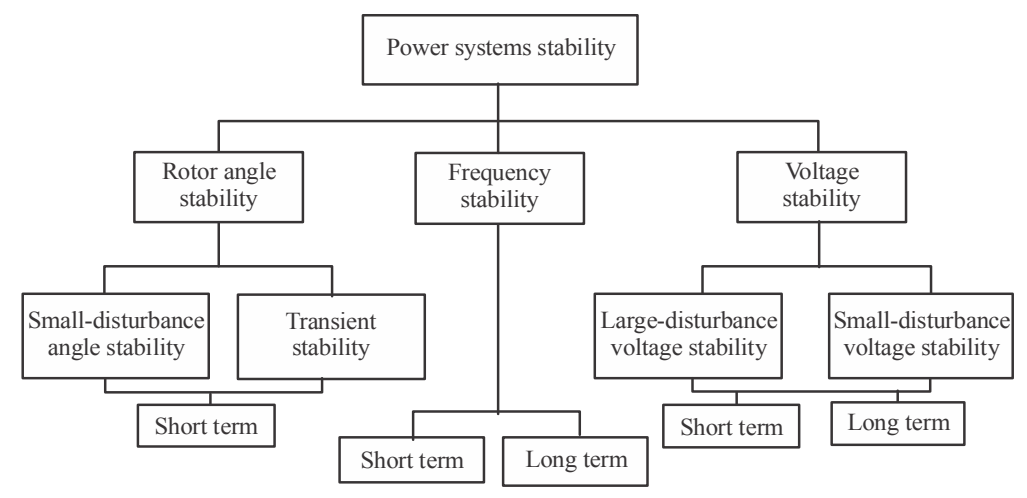

Fig. 1: Power system stability classification (Kundur et al., 2004)

synchronization, low bus voltages, high frequency deviation, size of the disturbance and measures taken to enhance the power system stability.

Rotor angle stability is defined as the competency to maintain synchronous between machines in a system after a disturbance has occurred. Being subjected to a disturbance, synchronous machines start "swinging" with respect to each other. If one machine starts running faster than another, the deviation in angular position will increase and the fast machine will supply more loads. System speed will then decrease allowing the other machine's speed to increase until equilibrium is reached. Instability occurs when equilibrium is not reached and the speed of some machines increases until these machines are tripped (Machowski et al., 2011; Kundur et al., 2004). Rotor angle stability is a highly nonlinear, multi-dimensional problem (Kundur, 1994a, b).

Instability can be categorized into two different parts: aperiodic (or non-oscillatory) instability and oscillatory instability. Aperiodic instability is caused by a lack of synchronizing torque that is associated with rotor angle deviation while oscillatory instability is caused by a lack of damping torque associated with speed deviation. Instability problems are aperiodic and are mainly due to insufficient synchronizing torque (Cutsem, 2007; Taylor, 1994). Rotor angle stability consists only of short-term phenomena as the time frame is in the order of a few seconds to a few tens of seconds (Machowski et al., 2011; Kundur et al., 2004).

Large disturbance angular stability (transient stability) is a subsection of rotor angle stability and contains function of the power system to keep angular stability after major disturbances (e.g., shorting or disconnecting of the transmission line). The maximum time during which a disturbance can be applied without the system losing its stability is called Critical Clearing Time (CCT). Due to the highly nonlinear characteristics of transient stability, time domain simulation is used to solve the algebraic and differential equations in a power system using a step-by-step calculation procedure. Direct method can also be used to determine stability using Newton Raphson's second method. This method is not often used due to the complication of finding an adequate function and inability of defining a practical stability domain (Kundur et al., 2004; Kundur, 1994 a, b). Pattern recognition can also be a method for transient stability analysis by referring to past experience and applying it to current stability properties (Kundur, 1994a, b).

Small disturbance angular stability (small signal stability) is another subsection of rotor angle stability and it comprises of functions of the power system that sustain stability after experiencing small disturbances. A small disturbance is considered if the linearized system still exhibits the kinematics of the original system under this disturbance (Machowski et al., 2011; Kundur et al., 2004). Modal analysis method can be applied when a system is linearized. The modal analysis calculates the characteristics of modes (mode shapes, transfer functions and coupling coefficients) that are useful for improving damping. It uses the time domain simulation to visualize the results (Potamianakis and Vournas, 2006). The branching method is another way to evaluate the effect of large changes in small signal stability, unlike modal analysis where all system parameters are fixed (Van Cutsem, 2000; Chakravorty and Patra, 2016). As mentioned above, two types of rotor angular instability can occur. The presence of a complex conjugate eigenvalue with positive real part causes vibration instability as shown in Fig. 2. If the eigenvalues are positive and real, instability is an acyclic type as shown in Fig. 3.

Frequency stability is the capability of the power system to uphold stable frequencies following disturbances due to the discrepancy between generation and load. The system is said to have frequency stability if it can balance or restore power and load with minimal load trips. Time domain simulations are mainly used for frequency stability analysis as an appropriate representation of dynamic devices (Kundur et al., 2004).

In this study with the help of three-phase balance fault, transient stability analysis is carried out. Runga and Euler methods are used for analysing the swing behaviour of the system. A large number of simulations are 


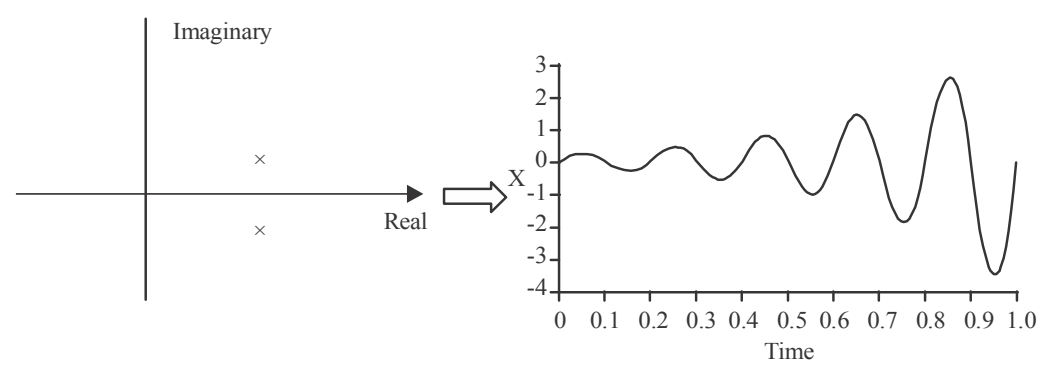

Fig. 2: Vibration instability (Pavella et al., 2000) (Oscillatory instability)

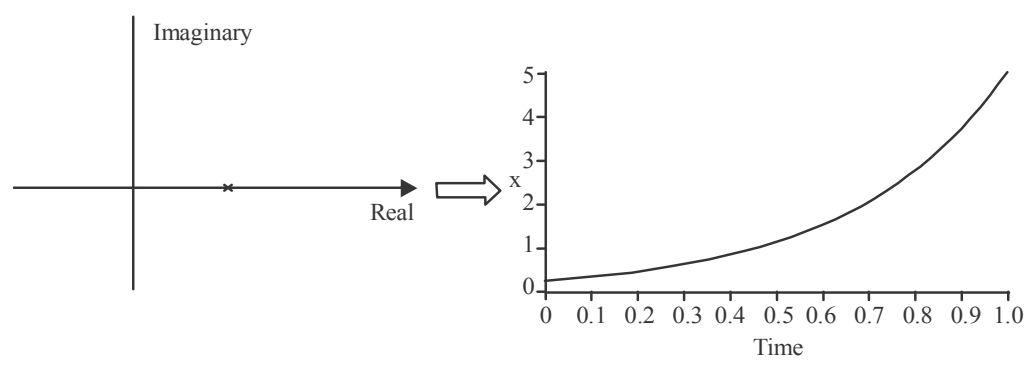

Fig. 3: Acyclic instability (Pavella et al., 2000) (Aperiodic instability)

performed during the planning stage of the system to obtain its accurate knowledge. The simulation of IEEE 9-bus system model is carried out in Power Word Simulator Software. The proposed work is tested on IEEE 9-bus power systems under normal and abnormal operating conditions (Machowski et al., 2011).

\section{Problem formulation}

Power flow study: Transient stability studies require knowledge of pre-fault voltage magnitude. Key information in the power flow study includes the bus voltage, phase angle of the bus voltage, the transmission line actual power and reactive power, the generator bus actual and reactive power and other variables. From load flow analysis, pre-fault conditions can be obtained by using Newton-Raphson method.

Newton-Raphson method is a useful method of networking large capacity load flow solutions convergence is not affected by reserve bus selection. This method starts with preliminary guessing of all unidentified variables such as voltage, voltage angle of the load bus and the voltage angle of the generator bus. A Taylor series is then obtained that ignores the higher order term for every power balance equation in the equation system. Firstly, study is performed for the existence of a load bus and a distant PQ bus. For an ith bus:

$$
\begin{gathered}
\mathrm{Pi}=\sum_{\mathrm{k}=1}^{\mathrm{n}}|\mathrm{Vi}\|\mathrm{Vk}\| \mathrm{Yik}| \cos (\theta \mathrm{ik}+\delta \mathrm{k}-\delta \mathrm{i})=\mathrm{Pi}(|\mathrm{V}|, \delta) \\
\mathrm{Qi}=\sum_{\mathrm{k}=1}^{\mathrm{n}}|\mathrm{Vi}||\mathrm{Vk} \| \mathrm{Yik}| \sin (\theta i \mathrm{k}+\delta \mathrm{k}-\delta \mathrm{i})=\mathrm{Qi}(|\mathrm{V}|, \delta)
\end{gathered}
$$

$$
\begin{aligned}
& |\mathrm{V}|=\left(\left|\mathrm{V}_{1}\right|,\left|\mathrm{V}_{2}\right|, \ldots \ldots \ldots,\left|\mathrm{V}_{\mathrm{n}}\right|\right)^{\mathrm{T}} \\
& \operatorname{Pi}(|\mathrm{V}|)=\operatorname{Pi}(\mathrm{x}) \\
& \mathrm{Qi}(|\mathrm{V}|)=\mathrm{Qi}(\mathrm{x}) \\
& \mathrm{x}=\left(\frac{\delta}{|\mathrm{V}|}\right) \\
& \operatorname{Pi}-\operatorname{Pi}(x)=0 \text { and } \quad \text { Qi-Qi }(x)=0 \\
& \mathrm{f}(\mathrm{x})=\left[\begin{array}{c}
\mathrm{P}(\text { scheduled })-\mathrm{P}(\mathrm{x}) \\
\mathrm{Q}(\text { scheduled })-\mathrm{Q}(\mathrm{x})
\end{array}\right]=\left[\begin{array}{c}
\Delta \mathrm{P}(\mathrm{x}) \\
\Delta \mathrm{Q}(\mathrm{x})
\end{array}\right]=0 \\
& \mathrm{f}(\mathrm{x})=\left[\begin{array}{l}
\Delta \mathrm{P}(\mathrm{x}) \\
\Delta \mathrm{Q}(\mathrm{x})
\end{array}\right]=\left[\begin{array}{l}
-\mathrm{J} 11(\mathrm{x})-\mathrm{J} 12(\mathrm{x}) \\
-\mathrm{J} 21(\mathrm{x})-\mathrm{J} 22(\mathrm{x})
\end{array}\right]=\left[\begin{array}{l}
\Delta \delta \\
\Delta|\mathrm{V}|
\end{array}\right] \\
& \Delta \delta=\left(\Delta \delta_{2}, \ldots \ldots, \Delta \delta_{n}\right)^{T} \\
& \Delta|\mathrm{V}|=\left(\Delta\left|\mathrm{V}_{2}\right|, \ldots \ldots \ldots, \Delta\left|\mathrm{V}_{\mathrm{n}}\right|\right)^{\mathrm{T}} \\
& J(x)=\left[\begin{array}{l}
-J 11(x)-J 12(x) \\
-J 21(x)-J 22(x)
\end{array}\right]
\end{aligned}
$$


Int. J. Elec. Power Eng., 13 (2): 19-29, 2019

$$
\begin{aligned}
& -\mathrm{J}_{11}(\mathrm{x})=\frac{\partial \mathrm{P}(\mathrm{x})}{\partial \delta} \\
& -\mathrm{J}_{12}(\mathrm{x})=\frac{\partial \mathrm{P}(\mathrm{x})}{\partial|\mathrm{V}|} \\
& -\mathrm{J}_{21}(\mathrm{x})=\frac{\partial \mathrm{Q}(\mathrm{x})}{\partial \delta} \\
& -\mathrm{J}_{22}(\mathrm{x})=\frac{\partial \mathrm{Q}(\mathrm{x})}{\partial|\mathrm{V}|} \\
& \frac{\partial \mathrm{Pi}(\mathrm{x})}{\partial \delta \mathrm{k}}, \frac{\partial \mathrm{Pi}(\mathrm{x})}{\partial|\mathrm{Vk}|}, \frac{\partial \mathrm{Qi}(\mathrm{x})}{\partial \delta \mathrm{k}}, \frac{\partial \mathrm{Qi}(\mathrm{x})}{\partial|\mathrm{Vk}|} \\
& \frac{\partial \mathrm{Pi}(\mathrm{x})}{\partial \delta \mathrm{k}}=-|\mathrm{Vi}||\mathrm{Vk} \| \mathrm{Yik}| \sin (\theta \mathrm{ik}+\delta \mathrm{k}-\delta \mathrm{i})(\mathrm{i}=\mathrm{k}) \\
& \frac{\partial \mathrm{Pi}(\mathrm{x})}{\partial \delta \mathrm{k}}=\sum_{\substack{\mathrm{k}=1 \\
\mathrm{k} \neq \mathrm{i}}}^{\mathrm{n}}|\mathrm{Vi}||\mathrm{Vk}||\mathrm{Yik}| \sin (\theta \mathrm{ik}+\delta \mathrm{k}-\delta \mathrm{i})(\mathrm{i}=\mathrm{k}) \\
& \frac{\partial \mathrm{Pi}(\mathrm{x})}{\partial|\mathrm{Vk}|}=|\mathrm{Vi}||\mathrm{Vk}||\mathrm{Yik}| \cos (\theta \mathrm{ik}+\delta \mathrm{k}-\delta \mathrm{i})(\mathrm{i} \neq \mathrm{k}) \\
& \frac{\partial \mathrm{Pi}(\mathrm{x})}{\partial|\mathrm{Vk}|}=2|\mathrm{Vi}||\mathrm{Yii}| \cos \theta \mathrm{ii}+ \\
& \sum_{\substack{k=1 \\
k \neq i}}^{n}|V k||Y i k| \cos (\theta i k+\delta k-\delta i)(i=k)
\end{aligned}
$$

$$
\begin{gathered}
\frac{\partial \mathrm{Qi}(\mathrm{x})}{\partial \delta \mathrm{k}}=|\mathrm{Vi}||\mathrm{Vk}||\mathrm{Yik}| \sin (\theta \mathrm{ik}+\delta \mathrm{k}-\delta \mathrm{i})(\mathrm{i} \neq \mathrm{k}) \\
\frac{\partial \mathrm{QPi}(\mathrm{x})}{\partial \delta \mathrm{k}}=\sum_{\substack{\mathrm{k}=1 \\
\mathrm{k} \neq \mathrm{i}}}^{\mathrm{n}}|\mathrm{Vi}||\mathrm{Vk}||\mathrm{Yik}| \operatorname{con}(\theta \mathrm{ik}+\delta \mathrm{k}-\delta \mathrm{i})(\mathrm{i}=\mathrm{k}) \\
\frac{\partial \mathrm{Qi}(\mathrm{x})}{\partial|\mathrm{Vk}|}=|\mathrm{Vi}||\mathrm{Yik}| \sin (\theta \mathrm{ik}+\delta \mathrm{k}-\delta \mathrm{i})(\mathrm{i} \neq \mathrm{k}) \\
\frac{\partial \mathrm{Qi}(\mathrm{x})}{\partial[\mathrm{Vk})}=2|\mathrm{Vi}||\mathrm{Yii}| \sin \theta \mathrm{ii}+ \\
\sum_{\substack{\mathrm{k}=1 \\
\mathrm{k} \neq \mathrm{i}}}^{\mathrm{n}}|\mathrm{Vk} \| \mathrm{Yik}| \sin (\theta \mathrm{ik}+\delta \mathrm{k}-\delta \mathrm{i})(\mathrm{i}=\mathrm{k})
\end{gathered}
$$

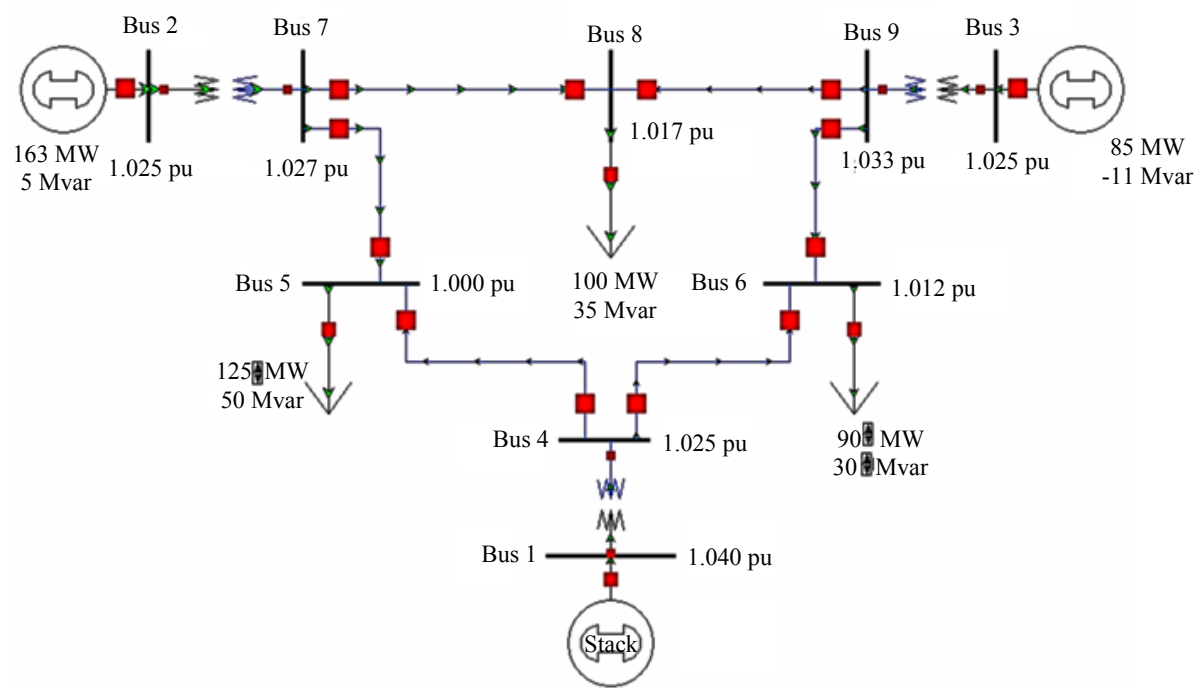

Fig. 4: IEEE 9-bus test system 
Int. J. Elec. Power Eng., 13 (2): 19-29, 2019

Table 1: Load flow analysis

\begin{tabular}{lccccccrrr}
\hline Name & Area name & Nom $(\mathrm{kV})$ & PU $(\mathrm{V})$ & Volt $(\mathrm{kV})$ & Angle (Deg.) & Load (MW) & Load (Mvar) & Gen (MW) & Gen Mvar \\
\hline Bus 1 & 1 & 16.50 & 1.04000 & 17.160 & 0.00 & 0 & 0 & 71.63 & 27.91 \\
Bus 2 & 1 & 18.00 & 1.02500 & 18.450 & 9.35 & 0 & 0 & 163.00 & 4.90 \\
Bus 3 & 1 & 13.80 & 1.02500 & 14.145 & 5.14 & 0 & 0 & 85.00 & -11.45 \\
Bus 4 & 1 & 230.00 & 1.02531 & 235.821 & -2.22 & 0 & 0 & 0 \\
Bus 5 & 1 & 230.00 & 0.99972 & 229.936 & -3.68 & 125.00 & 50.00 & 0 \\
Bus 6 & 1 & 230.00 & 1.01225 & 232.819 & -3.57 & 90.00 & 30.00 & 0 \\
Bus 7 & 1 & 230.00 & 1.02683 & 236.971 & 3.80 & 0 & & 0 \\
Bus 8 & 1 & 230.00 & 1.01727 & 133.971 & 13.4 & 100.00 & 35.00 & 0 \\
Bus 9 & 1 & 230.00 & 1.03269 & 237.519 & 2.44 & 0 & 0 & 0 \\
\hline
\end{tabular}

Table 2: Power flow analysis

\begin{tabular}{lllccccc}
\hline From bus & To bus & Branch device type & MW from & Mvar from & MVA from & MW loss & Mvar loss \\
\hline 8 & 9 & Line & -22 & -23.6 & 32.1 & 0.1 & -21 \\
6 & 4 & Line & -28 & -16.9 & 32.9 & 0.1 & -16 \\
7 & 8 & Line & 78.8 & -0.8 & 78.9 & 0.5 & -12 \\
9 & 6 & Line & 63.3 & -17.8 & 65.7 & 1.5 & -31 \\
5 & 4 & Line & -43 & -39.6 & 58.5 & 0.3 & -16 \\
7 & 5 & Line & 84.2 & -10.1 & 84.8 & 2.2 & 0 \\
4 & 1 & Transformer & -72 & -24.8 & 75.8 & 0 & 3.15 \\
2 & 7 & Transformer & 163 & 4.9 & 163 & 0 & 15.8 \\
9 & 3 & Transformer & -85 & 15.6 & 86.4 & 0.1 \\
\hline
\end{tabular}

applied and the load flow is completed. Load flow analysis of the 9 bus system is performed using the adaptive Newton Raphson method as shown in Table 1.

Step 2: After load flow, initial parameters of the system, e.g., voltage at a bus, frequency of bus, bus power angle and rotor angle of a generator are studied as shown in Table 2 .

Step 3: Multiple contingencies at different times are applied and the output results are obtained by Power Word Simulator Software using the Runga and Euler methods.

Step 4: Compare the results of the three steps in both approaches and calculate which technique is superior to the transient stability analysis.

\section{RESULTS AND DISCUSSION}

Simulations on IEEE 9-bus test system are performed with three-phase faults that occurred at $1 \mathrm{sec}$ at bus 5 in the system. Table 1 and 2 shows results of simulation with load flow analysis and power flow analysis, respectively. At $1.03 \mathrm{sec}$, fault is cleared which means $0.03 \mathrm{sec}$ is fault clearing time. The simulations are also done with abrupt changes in load as a result of fault occurred in the transmission line between bus 5 and bus 7 at $1 \mathrm{sec}$. At $1.03 \mathrm{sec}$ fault is cleared which means $0.03 \mathrm{sec}$ is fault clearing time. The simulation is also performed with a single generator outage from a system at $1.03 \mathrm{sec}$. As a result voltage of generator- 2 drops to zero. The simulation is also carried out when $50 \%$ of sudden loads increase on bus-5 at $1.03 \mathrm{sec}$. Resultant frequency of multiple machines decreases due to the load increase. The simulation is also done when $50 \%$ of sudden loads decrease on bus-5 at $1.03 \mathrm{sec}$. Resultant frequency of multiple machine increases due to load increases. The simulation is also performed with blackouts. A system can no longer supply loads under Blackout (Gomes et al., 2003). The simulation results of the rotor angle and frequency for five different contingencies of the multi-machine power system of Fig. 4 are shown in Fig. 5-14.

Case 1: Three phase balanced fault occurs on transmission line between bus 5 and bus 7 at $1 \mathrm{sec}$ and fault is cleared at $1.1 \mathrm{sec}$. The rotor angle of all three generators is shown in Fig. 5. Rotor angle deviation is maximum in generator ' 2 ' as well as in generator ' 3 ' due to less distance from fault point as compared to generator ' 1 ' but after sometime system becomes stable. Increasing the critical clearing time also increases the angle difference. This means that the system is in an unstable mode. The system will be out of synchronization if more time is required to clear the fault, so, the critical clearing time must be very small to keep the system in synchronization (Kumar et al., 2012). The frequency of all buses is shown in Fig. 6. The frequency of the connected system also changes due to fault on transmission line between bus ' 5 ' and bus ' 7 '. The frequency of the system increases because of less loading on system as load at bus ' 5 ' is removed due to fault.

Case 2: When load suddenly increase by $50 \%$ on bus ' 5 ' at $1 \mathrm{sec}$ and load is immediately removed at $1.1 \mathrm{sec}$. The rotor angle of all three generators are affected as shown in Fig. 7, however, after sometime the system becomes 


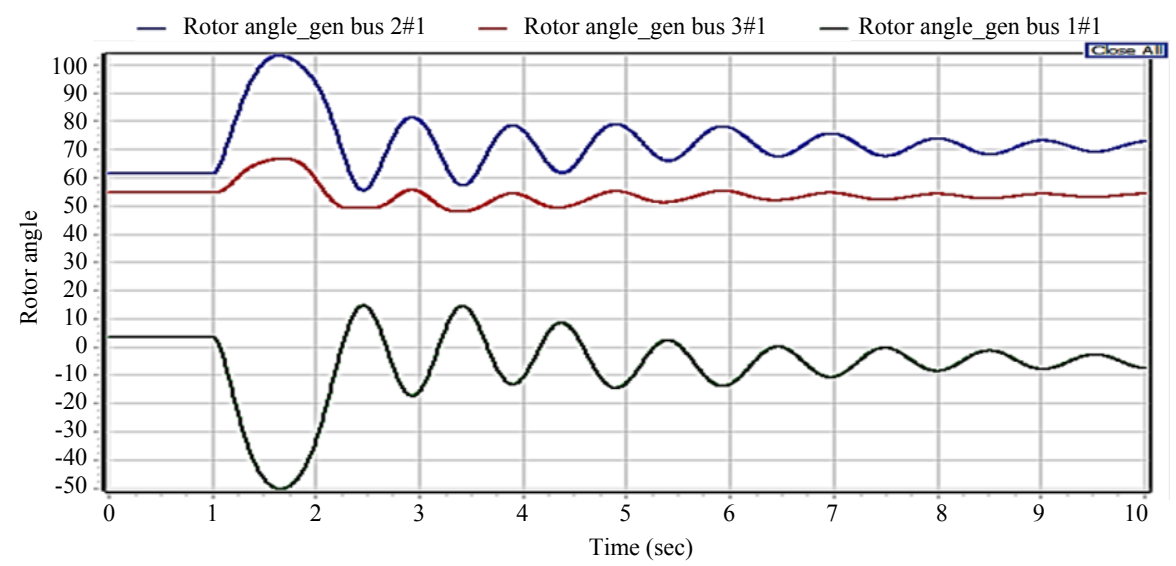

Fig. 5: Rotor angle vs. time (Power angle vs. time)

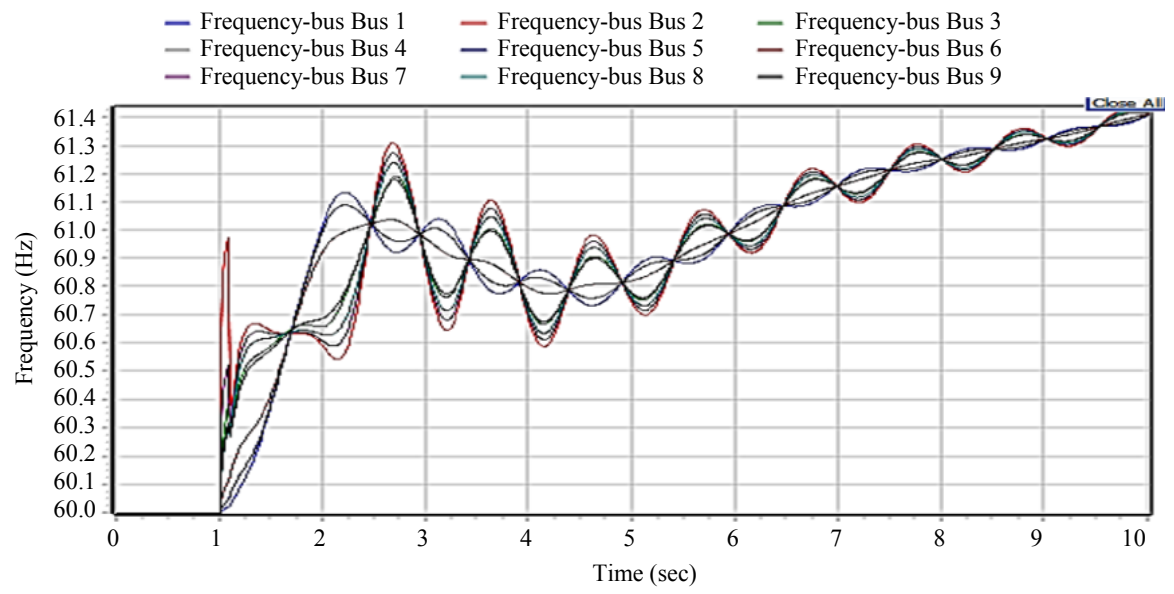

Fig. 6: Bus frequency vs. time (Frequency of all buses)

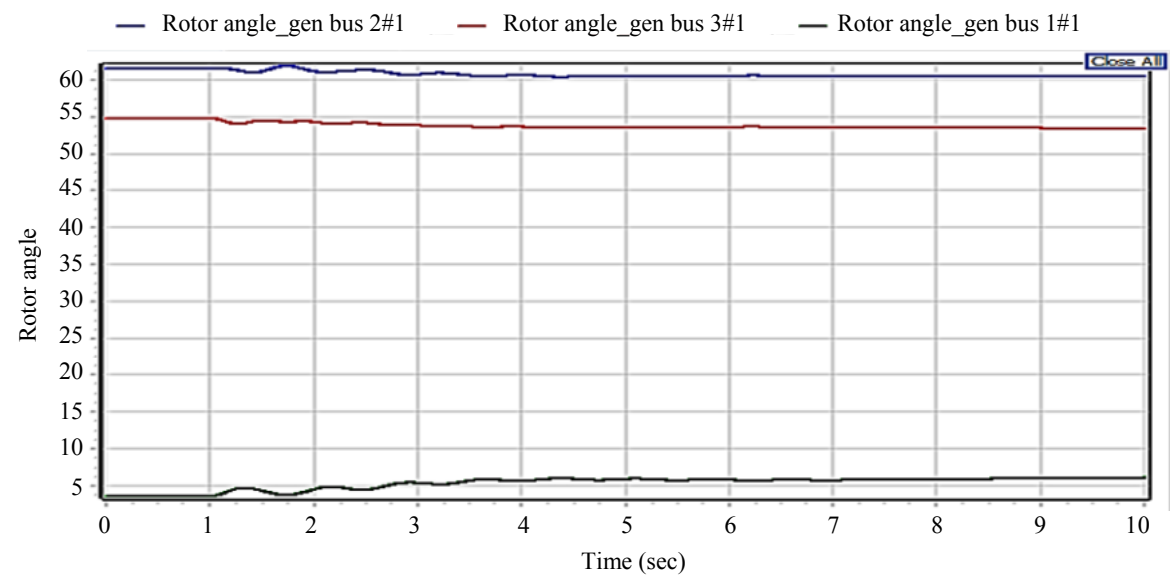

Fig. 7: Rotor angle vs. time (Power angle vs. time)

stable. The frequency of all buses is shown in Fig. 8. The frequency of the connected system also changes due to sudden load changes at bus ' 5 '. The frequency of the system decreases because the system has heavy load as load at bus ' 5 ' increases due to sudden loading. 
Int. J. Elec. Power Eng., 13 (2): 19-29, 2019

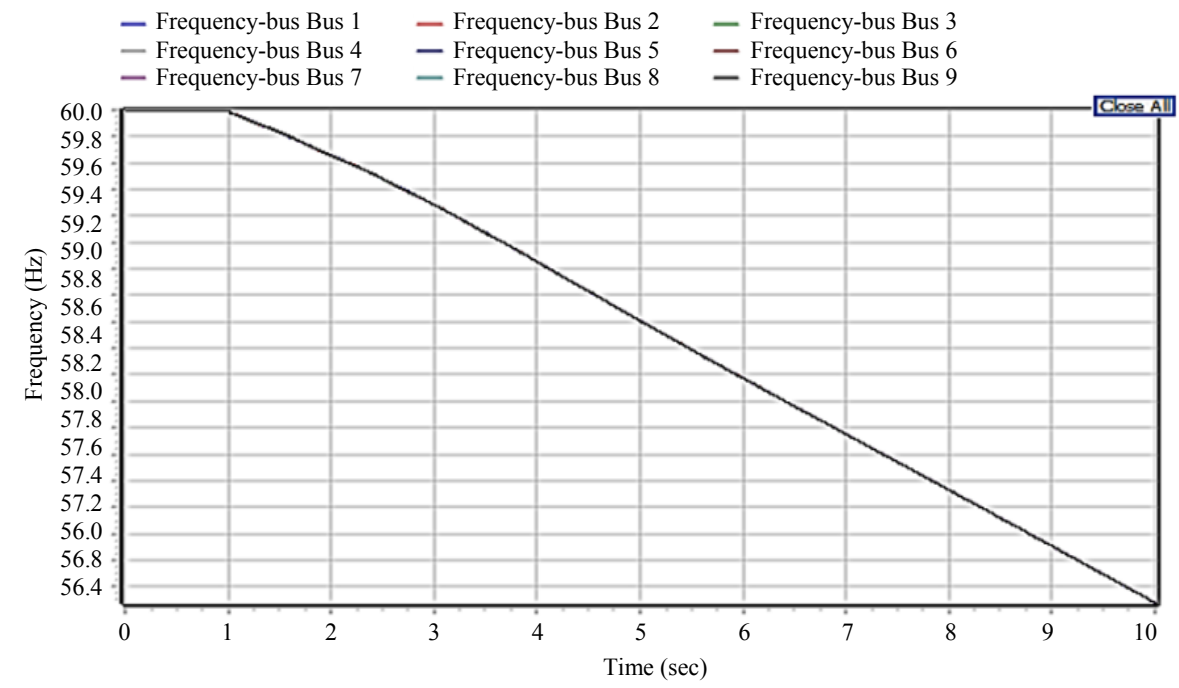

Fig. 8: Bus frequency vs. time

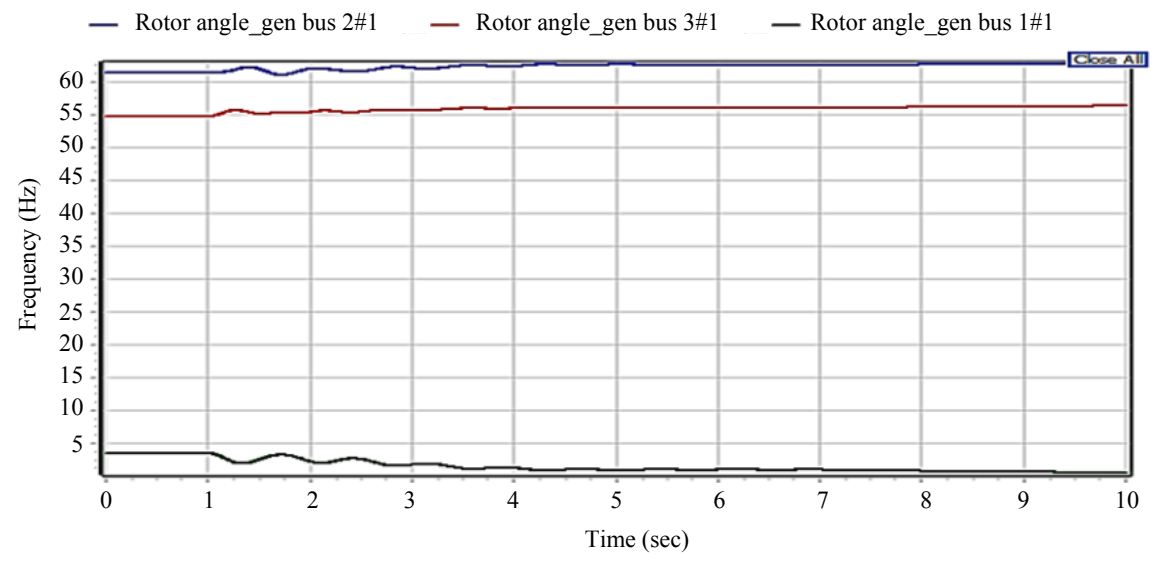

Fig. 9: Rotor angle vs. time

Case 3: When load suddenly decrease by $50 \%$ on bus ' 5 ' at $1 \mathrm{sec}$ and then load is removed at $1.1 \mathrm{sec}$. The rotor angle of all three generators is shown in Fig. 9. There is rotor angle deviation in all three generators, however, after sometime system is stable. But increasing the critical clear time also increases the angle difference. This means that the system is in an unstable mode. The system will be out of synchronization, if more time is required to clear the fault, so, the critical clearing time must be very short to keep the system in sync (Kumar et al., 2012). The frequency of all buses is shown in Fig. 10. The frequency of the connected system also changes due to sudden load changes at bus ' 5 '. The frequency of the system increases because the system has less loading as load at bus ' 5 ' decreases due to sudden removing of load.

Case 4: Three-phase balanced fault occurs on bus 5 at 1 $\mathrm{sec}$ and fault is cleared at $1.1 \mathrm{sec}$. The rotor angle of all three generators is shown in Fig. 11. Rotor angle deviation is maximum in generator ' 2 ' as well as in generator ' 3 ' due to less distance from fault point as compared to generator ' 1 ' but after sometime system is stable. The frequency of all buses is shown in Fig. 12. The frequency of the connected system also changes due to a three-phase balanced fault at bus ' 5 '. The frequency of the system increases because system has less loading as load at bus ' 5 ' remove due to three-phase balanced fault.

Case 5: In this case, we consider outage of single generator from the system at $1 \mathrm{sec}$. The rotor angle of all three generators is shown in Fig. 13. There is rotor angle deviation in generator ' 1 ' and generator ' 3 '. Generator ' 2 ' has no rotor angle deviation due to outage from the system. The frequency of all buses is shown in Fig. 14. The frequency of connected system also changes due to 
Int. J. Elec. Power Eng., 13 (2): 19-29, 2019

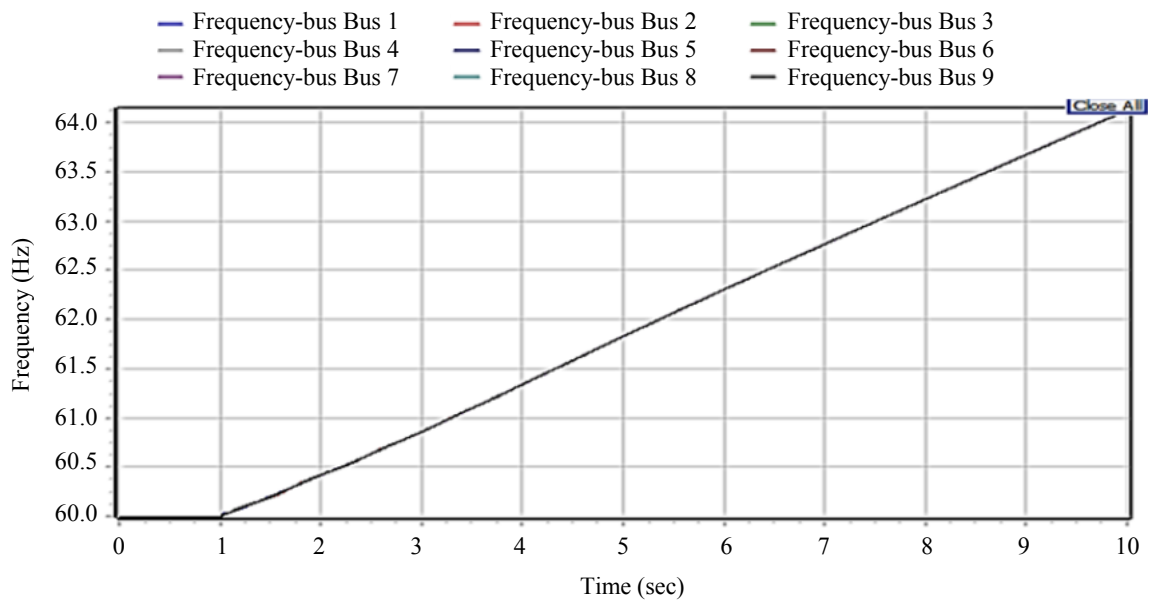

Fig. 10: Bus frequency vs. time (Frequency vs. time)

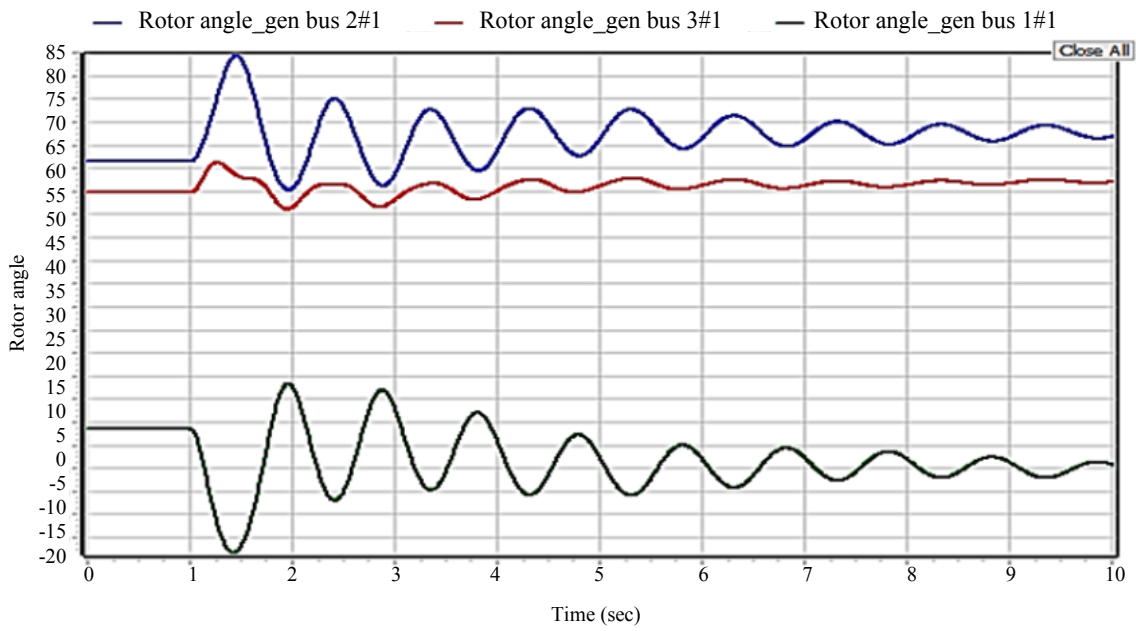

Fig. 11: Rotor angle vs. time

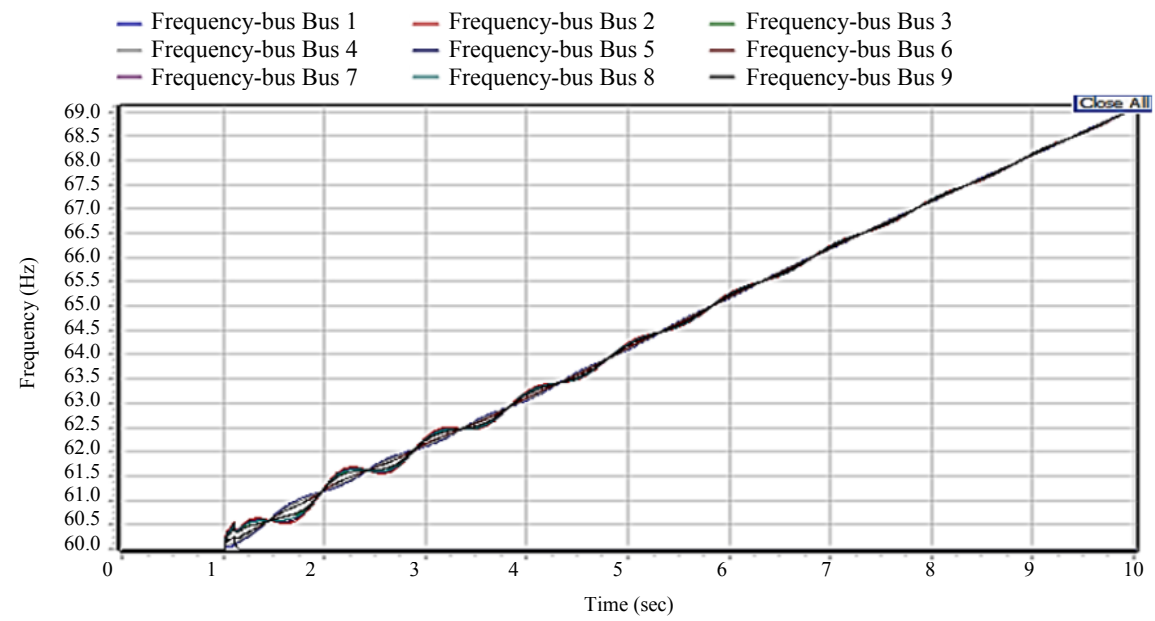

Fig. 12: Bus frequency vs. time 


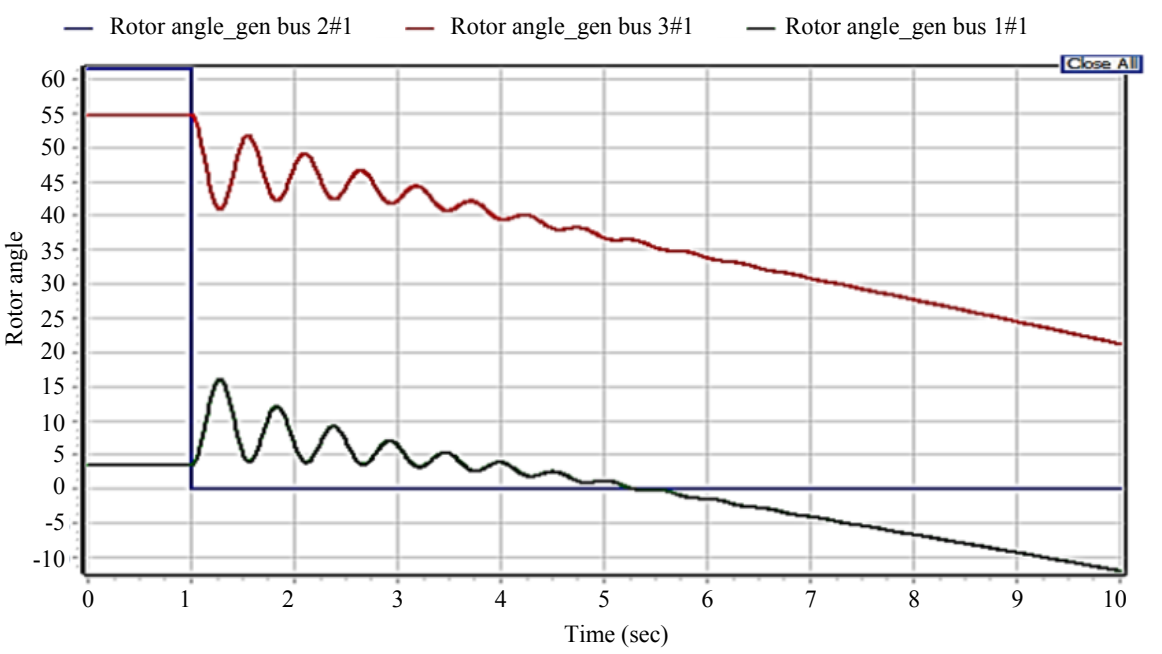

Fig. 13: Rotor angle vs. time

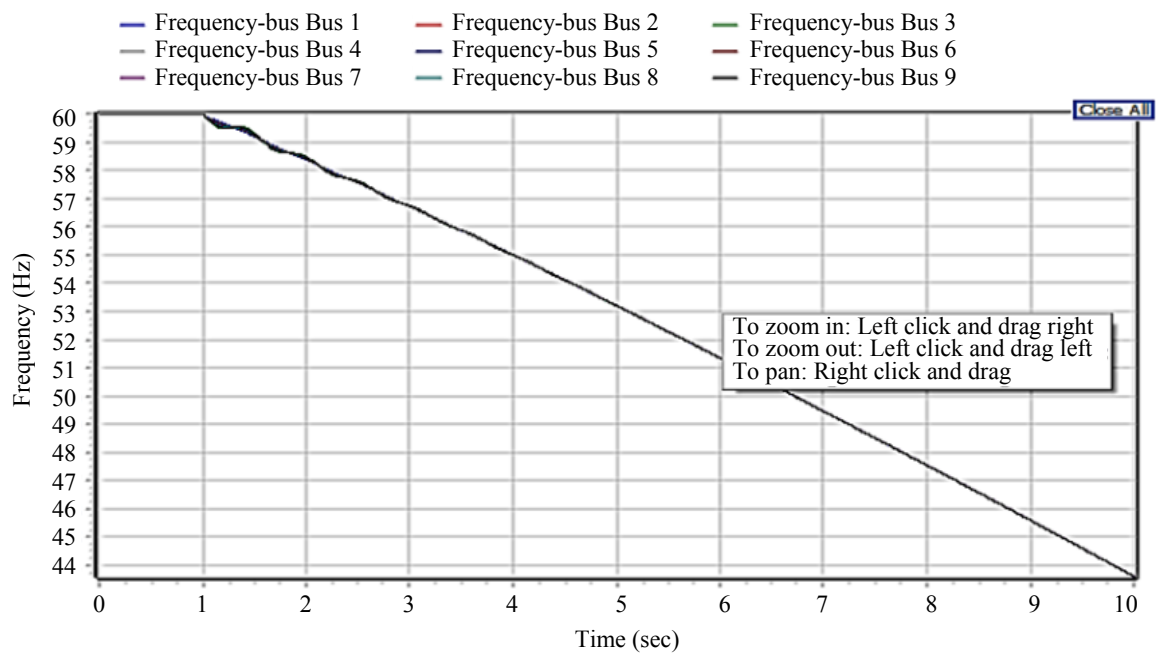

Fig. 14: Bus frequency vs. time

an outage of generator ' 2 '. The frequency of system decreases because system has less generation due to an outage of a single generator.

Case 6: Power outages in the power system can occur in several ways. The cause of the power failure may be an overload of the transmission line, ice coating of the track, protection or malfunction of the control system. Blackouts as shown in Fig. 15 can be prevented through proper control strategies in a systems to prevent from contingency, maintain load-generation balance and cascade to more fault contingencies.

When we increase load on bus 5 , a transmission line trips between bus 4 and bus 5 . When a line trips, the rest of the lines must carry the power, thus, consume more reactive power and reduce the voltage at the load center without affecting the frequency. Shortage of reactive power causes more voltage drop at stressed line loading conditions. Therefore, the voltage become as a key stress indicator of the power system rather than the frequency. Also, the voltage drop at the load center indicates that the systems will experience the low frequency after it breaks up into islands.

To analyse the effect of fault clearing on transient stability, fault is being removed after $1.033 \mathrm{sec}$. The maximum rotor angle changes $106.487^{\circ}$ by Runga method and $108.685^{\circ}$ by Euler method as shown in Table 3 . Comparing the two methods, the Runga method provides a faster response than the Euler method as shown in Fig. 16. The maximum change in rotor angle is $108.685^{\circ}$, the system is cleared after $1.033 \mathrm{sec}$ and after sometime system is stable. Increasing the critical clearing 


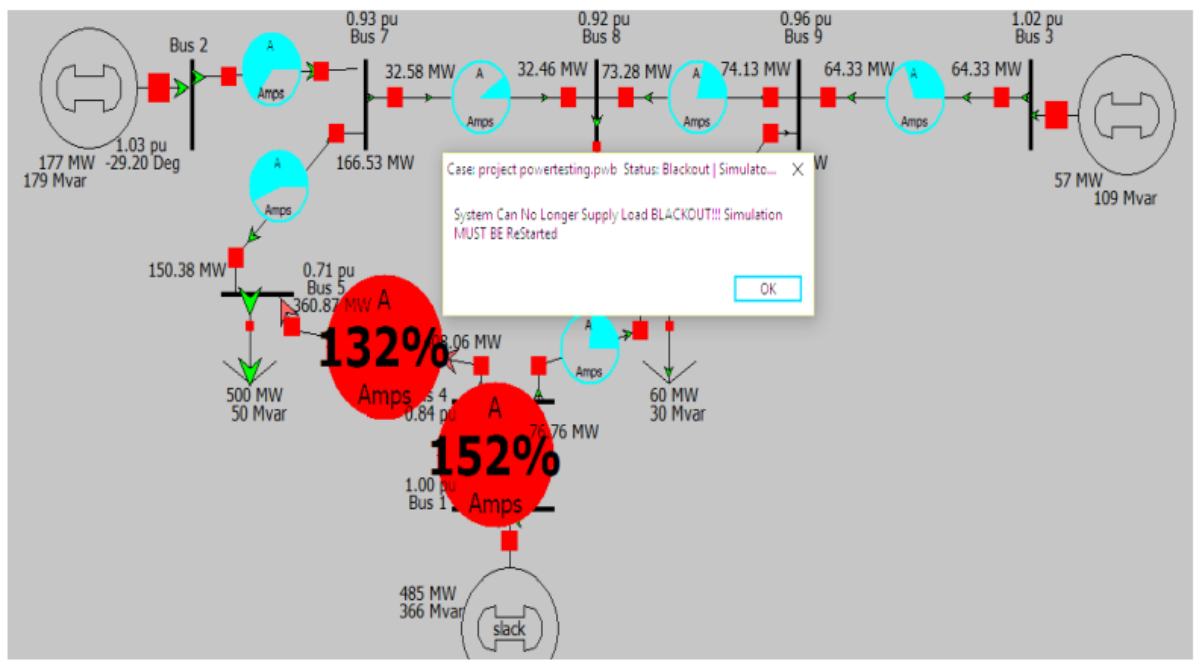

Fig. 15: Blackout

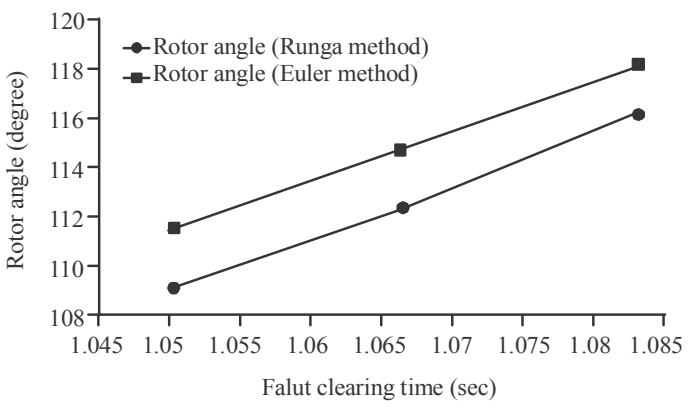

Fig. 16: Comparison between Runga and Euler method

Table 3: Comparison between Runga and Euler method

\begin{tabular}{lcc}
\hline $\begin{array}{l}\text { Fault clearing } \\
\text { time }\left(\mathrm{t}_{\mathrm{c}}, \mathrm{sec}\right)\end{array}$ & $\begin{array}{c}\text { Rotor angle (runga } \\
\text { method) }(\mathrm{deg})\end{array}$ & $\begin{array}{c}\text { Rotor angle (euler } \\
\text { method) }(\mathrm{deg})\end{array}$ \\
\hline 1.033 & 106.487 & 108.685 \\
1.05 & 109.063 & 111.448 \\
1.066 & 112.238 & 114.760 \\
1.083 & 116.237 & 118.170 \\
\hline
\end{tabular}

time also, increases the rotor angle difference. This means that the system will be then in unstable mode and it will be out of synchronization and more time must be required to clear the fault. It is because of this reason that the critical clearing time must be very short to keep the system in synchronization (Kumar et al., 2012).

\section{CONCLUSION}

In order to analyse the system behaviour, the simulation model of the IEEE 9-bus system has been build and related simulation results have been presented. It is concluded that power system should have very low critical clearing time to operate the relays of faulty section in order to isolate it within very short time, thus, the system can obtain the stability otherwise it will go out of synchronism. In this research work, load studies are performed to analyse the transient stability of the system. The behaviour of three-phase balanced fault and impact of load switching is also investigated. That reveal that the protection system provided for the system should have a fast response. Accordingly, fast fault clearing and load shedding methodologies can be adopted for system stability.

\section{REFERENCES}

Chakravorty, M. and S. Patra, 2016. Voltage stability analysis using conventional methods. Proceedings of the 2016 International Conference on Signal Processing, Communication, Power and Embedded System (SCOPES'16), October 3-5, 2016, IEEE, Paralakhemundi, India, pp: 496-501.

Cutsem, V., 2007. Voltage Stability of Electric Power System. 1st Edn., Technology and Engineering, Springer, New York.

Duan, C., L. Jiang, W. Fang and J. Liu, 2016. Moment-SOS approach to interval power flow. IEEE. Trans. Power Syst., 32: 522-530.

Gomes, S., N. Martins and C. Portela, 2003. Computing small-signal stability boundaries for large-scale power systems. IEEE. Trans. Power Syst., 18: 747-752. Kaur, R. and E.D. Kaur, 2016. Transient stability analysis of IEEE 9 bus system in power world simulator. Int. J. Eng. Res. Appl., 6: 35-39.

Kumar, S.N., M.K. Kirar and G. Agnihotri, 2012. Transient Stability analysis of the IEEE 9- Bus electric power system. Intl. J. Sci. Eng. Technol., 1: 161-166.

Kundur, P. and L. Wang, 2002. Small signal stability analysis: Experiences, achievements and challenges. Proceedings of the International Conference on Power System Technology, October 13-17, 2002, IEEE, Kunming, China, pp: 6-12. 
Kundur, P., 1994a. Power System Stability and Control. McGraw-Hill Professional, New York, USA., ISBN-13: 978-0070359581, Pages: 1176.

Kundur, P., 1994b. Power System Stability and Control. 1st Edn., McGraw-Hill Professional, USA., ISBN-10: 007035958X.

Kundur, P., J. Paserba, V. Ajjarapu, G. Andersson and A. Bose et al., 2004. Definition and classification of power system stability IEEE/CIGRE joint task force on stability terms and definitions. IEEE Trans. Power Syst., 19: 1387-1401.

Machowski, J., J.W. Bialek and J. Bumby, 2011. Power System Dynamics: Stability and Control. 2nd Edn., John Wiley \& Sons, Hoboken, New Jersey, USA., ISBN: 9781119965053 , Pages: 658.
Makarov, Y.V., Z.Y. Dong and D.J. Hill, 1998. A general method for small signal stability analysis. IEEE. Trans. Power Syst., 13: 979-985.

Pavella, M., D. Ernest and D. Ruiz-Vega, 2000. Transient Stability of Power Systems: A Unified Approach to Assessment and Control. Kluwer Academic Publishers, Dordrecht.

Potamianakis, E.G. and C.D. Vournas, 2006. Short-term voltage instability: Effects on synchronous and induction machines. IEEE. Trans. Power Syst., 21: 791-798.

Taylor, C.W., 1994. Power System Voltage Stability. 1st Edn., McGraw-Hill, Ohio, USA., ISBN: 0-07063184-0.

Van Cutsem, T., 2000. Voltage instability: Phenomena, countermeasures and analysis methods. Proc. IEEE., 88: 208-227. 